\title{
Um Dispositivo de Sensoriamento para Determinação de Desempenho de Tratores Agrícolas
}

\author{
Daniel C. de Souza, Alexandre Russini, Rogério R. Vargas, Cristiano Galafassi, Luis D. N. Martins \\ Laboratório de Sistema Inteligentes e Modelagem - Universidade Federal do Pampa, Campus Itaqui \\ danielciro6@gmail.com, \{alexandrerussini, rogeriovargas, cristianogalafassi\}@unipampa.edu.br, \\ luisdavidmartins@outlook.com
}

\begin{abstract}
Resumo: O presente trabalho descreve o desenvolvimento de uma instrumentação eletrônica para determinar o desempenho de tratores agrícolas em pista de concreto e em solo firme utilizando um conjunto de sensores com auxílio de plataforma aberta. O trabalho foi desenvolvido utilizando a plataforma Arduino, composta por uma placa MEGA, PRÓ MINI, GPS, Display, Capacitores, Reguladores de Tensão, Dissipador de Calor, Jumpers, Modulo SD CARD, Botão Liga e Desliga, Adaptador VGA macho DB15 e um Case, que serviram como componentes para construção do Datalogger, na qual serviu para armazenamento de dados oriundos dos sensores instalados em diferentes pontos do trator agrícola. Os dados armazenados pela instrumentação permitem determinar de forma precisa o desempenho de tratores quando em tração nos diferentes tipos de superfície propostos.
\end{abstract}

Palavras-chave: Datalogger, Trator, Potência.

\section{Introdução}

Tratores agrícolas são uma fonte utilizada nas operações de preparo do solo, independente da sua potência. No Brasil, como a área de cultivo vem aumentando gradualmente, a aplicação de tecnologias para atender o agronegócio vem sofrendo um avanço gradativo. Esses avanços estão ligados às áreas de tecnologia da informação e comunicação e automação que permitiram a criação de plataformas microcontroladas, visando à automatização de determinados processos de produção, engenharia e computação, contribuindo para melhoraria das condições de trabalho de todos os envolvidos em cada processo.

No caso da agricultura, com o aumento de produtividade, esses controladores ajudam na otimização de recursos contribuindo para um melhor planejamento e melhor uso das máquinas e implementos agrícolas, em função do alto capital investido e, principalmente, em relação aos custos variáveis como, por exemplo, o combustível. Isso requer eficiência no uso das máquinas para que não incorra em prejuízo na atividade [1].

Datalogger, é um registrador eletrônico de dados que realiza medições em um set tempo e os armazena em dispositivos ou mesmo em sua própria memória, ou seja, é um dispositivo de aquisição dados [2]. De acordo com Esser [3], dispositivos como esse costumam ser compactos, de fácil manuseio, equipados com uma bateria, um microprocessador interno, também um sistema armazenamento de dados e, composto por um ou mais sensores e podem ser um instrumento de coleta de dados multicanal equipado com um ou mais sensores externos. Eles também podem utilizar diversas plataformas para o seu processamento como, por exemplo, a plataforma Arduino que consiste em uma plataforma Open-source que se baseia em hardware e software para que pode ser utilizada em as áreas como automação e robótica [4]. Nela pode-se adicionar diversos tipos de componentes eletrônicos direcionados e programados para uma determinada atividade.

No caso específico da agricultura, o desenvolvimento de uma instrumentação para determinar o desempenho de um trator em operação indiferente de marca ou modelo, torna-se importante a fim de se realizar seu correto dimensionamento, além de auxiliar empresas fabricantes na adequação de seus produtos conforme a necessidade dos produtores.
Assim, um sistema formado por um conjunto de sensores e uma unidade de armazenamento (Datalogger) se faz necessário para obtenção dos dados referentes ao desempenho de um trator agrícola visando à realização de uma determinada análise específica [1].

Atualmente, existem pesquisadores de diferentes instituições de ensino e pesquisa carreando esforços no desenvolvimento de instrumentações eletrônicas, com a mesma finalidade. Pode-se citar, por exemplo, o trabalho de Gabriel Filho [5], onde foi desenvolvido um carro dinamométrico, denominado UMEB (Unidade Móvel de Ensaio da Barra de Tração) que é uma bancada de instrumentação com painéis de leitura e de aquisição de dados para se obter dados referentes a força de tração desempenhada por tratores. Serrano [6] utilizou um sistema Datatronic, com um computador portátil IBM Compaq Armada 1520, a placa de aquisição de dados do tipo PCMCIA, modelo DAQCard-1200 da National Instruments, para obtenção de dados de desempenho de tratores em tração, utilizando sensores disponíveis no mercado, o que determina um custo elevado na aquisição. Russini [7] desenvolveu uma instrumentação eletrônica para aquisição de dados para determinação da força de tração, consumo de combustível, velocidade das rodas e velocidade do trator, onde os dados coletados foram armazenados por um sistema de aquisição de dados, Datalogger modelo CR 1000 da marca Campbel. Porém, o autor explana o alto custo na criação da instrumentação. Outro estudo de desempenho de tratores em tração, realizado na Universidade Federal de Lavras [8], fez uso de uma placa eletrônica Arduino configurada para atuar conjuntamente com componentes eletrônicos de baixo custo com um módulo bluetooth e cartão de memória com acompanhamento, fazendo assim, o armazenamento em tempo real de dados.

Desta forma, o objetivo deste trabalho é demonstrar o desenvolvimento de uma instrumentação eletrônica, para determinar o desempenho em tração de um trator agrícola em pista de concreto e em solo firme, baseada na plataforma Arduino.

\section{Metodologia}

O trabalho foi desenvolvido no Laboratório de Sistemas Inteligentes e Modelagem (LabSIM), da Universidade Federal do Pampa Campus Itaqui-RS, latitude 29 07' 31 S" e longitude $56^{\circ} 33^{\prime} 11^{\prime \prime} \mathrm{W}$, com o uso da plataforma 
Arduino, composta por uma placa Mega que tem por função integrar o fluxo de informações para controle do software; uma placa Pró-Mini destinado para instalação semipermanente em objetos ou exposições, ou seja permite o uso de vários tipos de conectores ou cabos soldados diretamente à placa [9]; GPS; display (visor); capacitores; reguladores de tensão; dissipador de Calor; jumpers; módulo de memória $S D$ card; botão liga e desliga; adaptador VGA macho DB15 e uma caixa hermética. Todos esses componentes foram utilizados para a construção do Datalogger.

Além desses componentes, foram utilizados sensores magnéticos instalados nas rodas motrizes na qual tornase possível obter a rotação (RPM) e indiretamente a velocidade das rodas e patinamento. Uma célula de carga com capacidade de $50 \mathrm{kN}$ foi acoplada à barra de tração do trator, na qual visa a obter os valores de força de tração. Para determinação do consumo de combustível utilizou-se um fluxômetro e receptor GPS que obtêm a velocidade de deslocamento da máquina. Para isso, se fez o uso de um algoritmo específico na plataforma Arduino, que utiliza de bibliotecas livres nesta plataforma. Porém, foram necessárias modificações na programação visando a uma melhor adequação para esta ser utilizada no Datalogger.

A disposição do sistema de aquisição e armazenamento de dados, apresenta-se da seguinte forma:

- Datalogger: armazenamento dos dados dos sensores instalados no trator que também, por meio de um visor, demonstra se os dados foram registrados e armazenados no cartão SD;

- GPS: l ocalização em coordenadas geográficas e velocidade de deslocamento do trator (em tempo real expressada em $\mathrm{km} \cdot \mathrm{h}^{-1}$ );

- Medidor de fluxo de combustível: registro da quantidade de combustível consumida pelo trator em operação, em L.h ${ }^{-1}$;

- Célula de Carga: registro da força de tração (em $\mathrm{kg}^{-1}$ ) realizada pelo trator, em função da carga imposta pelo carro dinamométrico;

- Sensores magnéticos de roda: instalados nas rodas motrizes do trator, fornecem individualmente a rotação (rpm) e ambas rodas, sendo este parâmetro necessário para determinação do patinamento dos rodados.

Os valores obtidos pelos sensores instalados ao trator foram armazenados no cartão SD de forma contínua e cumulativa, de modo a evitar que as informações sejam perdidas. O arranjo da instalação da instrumentação, no trator, pode ser visualizado na figura 1.

Na figura 2 é apresentado o datalogger desenvolvido com a utilização da plataforma Arduino. Este fica disposto na cabine do trator e possui um display (um visor) onde se consegue visualizar, em tempo real, se a informação está em processo de armazenamento.

O conjunto de componentes que formam a instrumentação foram instalados sem que houvesse interferência na operação do trator durante a realização dos testes. Utilizou-se um trator da marca NEW HOLLAND modelo TL 75E (75cv), com tração dianteira auxiliar (TDA), equipado com pneus do R2. A massa do trator era de $3870 \mathrm{~kg}$, com distribuição estática de $39 \%$ e $61 \%$, entre os rodados dianteiros e traseiros, respectivamente. A relação entre massa/potência era $70,36 \mathrm{~kg} \mathrm{~kW}^{-1}$, superior à recomendada por Schlosser [10], onde a relação massa/potência ideal para operações agrícolas pesadas, com maiores exigências de força de tração, deve ficar em torno de $60 \mathrm{~kg} . \mathrm{kW}^{-1}$. Este trator teste tracionou um cavalo mecânico da marca SCANIA 112 HW (360 cv), caracterizado como carro dinamométrico com massa de $8700 \mathrm{~kg}$, podendo ser alterada com adição ou retirada de lastro, conforme a necessidade de frenagem. O carro dinamométrico foi utilizado como mecanismo de frenagem, impondo cargas alternadas ao trator, conforme demonstra o esquema da figura 3.

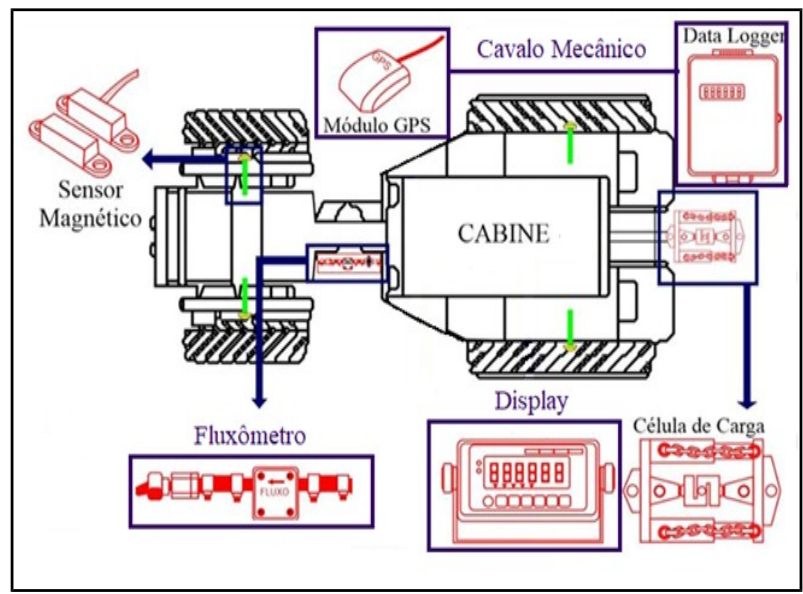

Figura 1. Instrumentação eletrônica instalada em um trator.

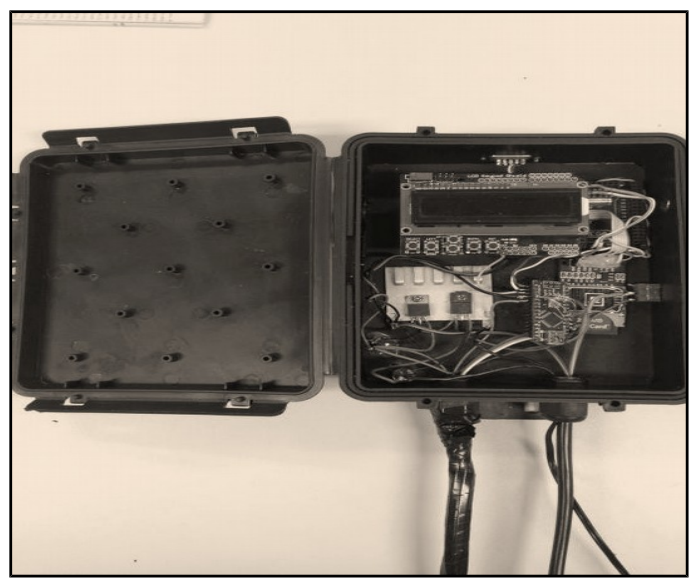

Figura 2. Datalogger utilizado para armazenamento de dados.

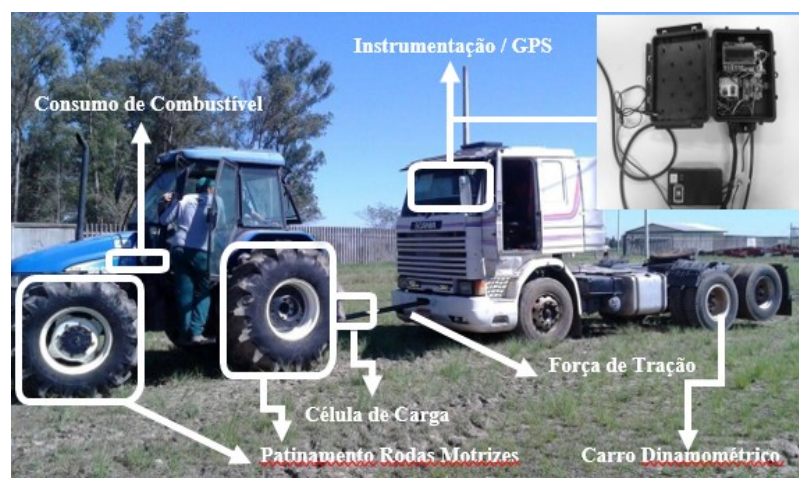

Figura 3. Trator instrumentado e carro dinamométrico. 
Para validação da instrumentação, o trator teste tracionou o carro dinamométrico em duas superfícies, pista de concreto e solo agrícola firme, sendo os dados obtidos comparados com a literatura existente [11]. Os valores dos parâmetros de desempenho como o patinamento e foi mantido em $10 \%$ e $15 \%$, em pista de concreto e solo firme com vegetação, respectivamente, conforme preconiza a Norma ASAE EP496.2 [12]. Os limites dos valores de patinamento, foram mantidos por meio do controle da carga imposta pelo carro dinamométrico, não havendo valores superiores aos estabelecidos.

A célula de carga obteve os valores de forças de tração exercida pela barra de tração em quatro diferentes velocidades de deslocamento. A partir dos dados obtidos referentes a velocidade e força de tração foi possível calcular a potência de tração desenvolvida pelo trator conforme a equação (1).

$$
P o t B t=\frac{F * V}{3,6}
$$

onde:

PotBt: potência de tração $(\mathrm{kW})$;

$F$ : força de tração $(\mathrm{kN})$;

$V$ : velocidade do trator $\left(\mathrm{km} \mathrm{h}^{-1}\right)$.

\section{Resultados}

Os resultados parciais de um teste de tração, referentes à força de tração, potência de tração em função da velocidade de deslocamento em uma dada condição, de configuração do trator, em pista de concreto e solo firme, podem ser visualizados na figura 4.
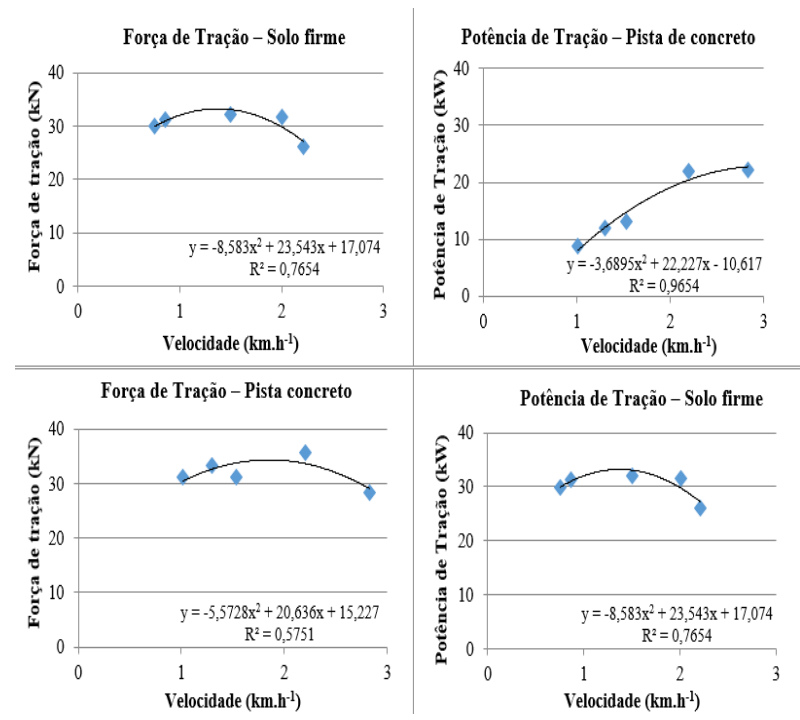

Figura 4. Força de tração e potência de tração em pista de concreto e solo firme.

Relata-se que o desempenho dos rodados no desenvolvimento da tração está relacionado aos parâmetros do solo, presença de resíduo ou cobertura morta, carga e pressão do rodado sobre o solo. Nesse caso, a variação de um destes fatores irá interferir diretamente na capacidade de tração [13]. Com relação à potência de tração observou-se para a pista de concreto um aumento de $20 \%$ em relação a potência de tração desenvolvida em solo firme. Esse comportamento está de acordo com o descrito por Márquez [14], onde a potência de tração de um trator está limitada à capacidade de este fixar-se ao solo, e interessa conseguir que a maior parte ou todo o peso, seja aproveitado na aderência das rodas ao solo.

\section{Discussão}

Os ensaios de trator em solo agrícola e em pista de concreto são meios de se obter informações das máquinas, principalmente no que diz respeito ao seu desenvolvimento de tração. Esses ensaios visam a obtenção do desempenho dos rodados em relação as características do solo, visando um melhor rendimento operacional.

Outros dados podem ser obtidos com a utilização do Datalogger desenvolvido, como o consumo horário de combustível e o patinamento das rodas motrizes do trator.

A partir de testes de tração utilizando esta instrumentação, é possível a formação de um banco de dados no intuito de geração de modelos matemáticos para estimativa do desempenho de tratores agrícolas em solos onde há plantação de arroz irrigado na Região Oeste do Rio Grande do Sul.

\section{Conclusões}

O uso de instrumentação eletrônica, utilizando plataforma aberta provou ser uma excelente alternativa para obtenção de dados referentes ao desempenho de tratores agrícolas. As vantagens de se usar a plataforma aberta estão relacionadas aos custos de criação da instrumentação bem como a facilidade da utilização de periféricos simples.

Desta maneira, a partir dos resultados obtidos no experimento realizado com a instrumentação, pode-se inferir que a instrumentação atingiu nível de resultados satisfatórios adequado para a realização de experimentos, demonstrando ser uma excelente ferramenta para a determinação do desempenho em tração de tratores agrícolas.

\section{Bibliografia}

[1] Russini, A. (2009) Projeto, construção e teste de instrumentação eletrônica para avaliação de desempenho de tratores agrícolas. Dissertação de Mestrado. Universidade Federal de Santa Maria. Programa de PósGraduação em Engenharia Agrícola.

(https://repositorio.ufsm.br/handle/1/7509?show=full)

[2] Santos， J. A. (2015) Instrumentação eletrônica com o Arduino aplicada ao ensino de física. Dissertação de Mestrado Profissional. Universidade Federal Rural de Pernambuco. Programa de Pós-Graduação em ensino de física.

(http://www1.fisica.org.br/mnpef/sites/default/files/dissert acao_JoseAltenis.pdf)

[3] Esser, J. C. (2008) Data logger: coletor de dados. Dissertação de Mestrado Lato Sensu. Centro Federal de Educação Tecnológica de Santa Catarina. Programa de Pós-Graduação em Desenvolvimento de Produtos Eletrônicos.

(http://www.professorpetry.com.br/Ensino/Defesas_Pos_G raduacao/Defesa\%2006_Jean\%20Carlos\%20Esser_Data \%20Logger\%20-\%20Coletor\%20de\%20Dados.pdf) 
[4] Cavalcante, M. M.; Silva, J. L. S.; Dantas, J. R. (2014) A Plataforma Arduino para fins didáticos: Estudo de caso com recolhimento de dados a partir do PLX-DAQ. Anais

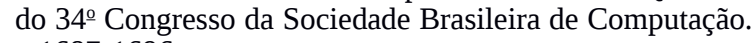
p.1687-1696.

[5] Gabriel Filho et al. (2008). UEMB- Unidade Móvel para ensaio na barra de tração. Revista Engenharia Agrícola 28(4): 782-789.

(http://www.scielo.br/pdf/eagri/v28n4/18.pdf)

[6] Serrano, J. M. P. R. Desempenho de tratores agrícolas em tração. Rev. Pesq. agropec. Bras. 42(7): 1021-1027, jul. 2007. (http://www.scielo.br/pdf/pab/v42n7/15.pdf)

[7] Russini, A. Estimativa do desempenho de tratores agrícolas em campo e pista a partir do ensaio dinamométrico. Tese de Doutorado. Universidade Federal de Santa Maria. Programa de Pós-Graduação em Engenharia Agrícola. (https://repositorio.ufsm.br/bitstream/handle/1/3599/RUSS INI\%2C\%20ALEXANDRE.pdf? sequence $=1 \&$ isAllowed $=\mathrm{y}$ )

[8] Corrêia Jr., D. (2017) Desenvolvimento e validação de um sistema embarcado para monitoramento de operações agrícolas com tratores. Tese de Doutorado. Universidade Federal de Lavras. Programa de Pós-Graduação em Engenharia Agrícola.

(http://repositorio.ufla.br/bitstream/1/13246/1/TESE_Dese nvolvimento\%20e\%20valida\%C3\%A7\%C3\%A3o\%20de \%20um\%20sistema\%20embarcado\%20para \%20monitoramento\%20de\%20opera \%C3\%A7\%C3\%B5es\%20agr\%C3\%ADcolas\%20com \%20tratores.pdf)
[9] Arduino. What is arduino. Online: https://www.arduino.cc/en/Guide/Introduction\#. Acesso em fev/2019.

[10] Schlosser, J. F. et al. (2005) Análise comparativa do peso específico dos tratores agrícolas fabricados no Brasil e seus efeitos sobre a seleção e uso. Revista Ciência Rural 35(1): 92-97. (http://www.scielo.br/pdf/cr/v35n1/a14v35n1.pdf )

[11] Gabriel Filho et al. (2010) Desempenho de um trator agrícola em três superficies de solo e quatro velocidades de deslocamneto. Revista Brasileira de Engenharia Agrícola e Ambiental 14(3): 33-339. Scielo. DOI: 10.1590/S1415-43662010000300015

[12] ASAE EP 496.2 FEB03. (2003) Agricultural Machinery Management. ASAE Standards: standards engineering practices data. St. Joseph: American Society of Agricultural Engineers, p. 366-372.

[13] Garcia, M. A. L. (2008) Avaliação de um sistema de plantio mecanizado de cana-de-açúcar. Universidade de São Paulo. Dissertação de Mestrado. Universidade de São Paulo. Programa de Pós-Graduação em Agronomia. DOI: 10.11606/D.11.2008.tde-03112008-154538

[14] Márquez, L. Tractores agrícolas: tecnología y utilización. Espanha: B\&H Grupo Editorial, 2012. 844p. 